\title{
Prediction of the Shear Strength of Concrete T-Beams Using Artificial Neural Networks Model
}

\author{
Asst. Lecture Roaa Talib Abd \\ Directorate of education vocational education/ Al Hawra Preparatory School
}

\begin{abstract}
This paper presents an application of artificial neural network (ANN) to develop a model for predicting the shear strength of T-beams. The required data has been taken from literature. Statistical tools like mean, standard deviation (SD), correlation coefficients (R) and mean absolute error (MAE) are adopted to verify the ANN model against the experimental results obtained from the literature and with the existing empirical codes. The produced ANN model is utilized to carry out a parametric analysis to study the impact of the multiple parameters on the shear strength of Tbeams. The parameters were shear span to depth ratios, effective depth, shear reinforcement, flange thickness, compressive strength of concrete, longitudinal steel ratio, flange width and web width. The outcomes of the parametric study show excellent trend agreement with the experimental database which emphasizes the statistical results. The overall analysis shows that the ANN model is more accurate than the guideline equations with respect to the experimental results and can be applied satisfactorily within the range of parameters covered in this study.
\end{abstract}

Keywords: Concrete; T-beams; Shear strength; Artificial neural networks; Parametric study.

\section{Introduction}

Although a number of researches have been conducted to estimate the shear strength of reinforced concrete beams for the last century, it is still hard to well predict actual shear strength because of shear behavior of reinforced concrete beams are very complicated due to many parameters such as concrete compressive strength, stirrup ratio, shear span-todepth ratio, longitudinal reinforcement ratio, dimensions of the flange part of slab and so on $[1,2$, $3,4,5,6,7,8]$. On evaluating shear strength of reinforced concrete beams, the shear design provisions around the world, such as American concrete institute and Canadian Standards Association, are much different from each other in the theoretical basis, specifically for reinforced concrete beams with stirrups $[9,10]$.

The objectives of this study are summarized as follows:
- Develop an artificial neural network model which can predict the shear strength of $\mathrm{T}$ beams.

- Compare the predicted strength of T-beams using the trained artificial neural network model with those calculated from some wellknown equations.

- Carry out a parametric study using the proposed model for the parameters affecting the shear strength of T-beams.

\section{Related works}

Recently, many researchers apply artificial neural network as a powerful tool to solve complex problems in civil engineering studies like predicting compressive strength of confined concrete [11], the strength of recycled aggregate concrete [12] and axial strength of composite column [13].The following are the more specific related works: 
Sanad and saka (2001) use the artificial neural network in predicting the ultimate shear strength of reinforced -concrete deep beams. The determined from ACI code method, strutand-tie method and Mau-Hsu method. [14]

Ashour et al. (2003) performed an empirical modelling of shear strength of reinforced concrete deep beam by genetic programming, which is a form of artificial intelligence. Good agreement between the model predictions and experiments has been achieved. [15]

Arafa et al (2011) applied to develop two models for predicting the ultimate shear strength of reinforced concrete deep beams for Normal Strength Concrete (NSC) and High Strength Concrete (HSC). The predicted shear strength values was compared with the experimental values and with the calculation from ACI code and achieve good agreements. [16]

Amani and Moeini (2012) used the Artificial Neural Network (ANN) and the Adaptive NeuroFuzzy Inference System (ANFIS) to predict the shear strength of Reinforced Concrete (RC) beams, and the models are compared with American Concrete Institute (ACI) and Iranian Concrete Institute (ICI) empirical codes. The models provides better prediction for shear strength. [17]

Vahidi and Rahimi (2016) developed a harmony search (HS) algorithm in ANN models. The model was validated and tested by 30 deep beams with opening. Comparisons between the predicted values and 30 test data showed that the developed ANN model resulted in improved statistical parameters with better accuracy than other existing equations. [18]

\section{Shear behavior of beams \\ 3.1. Beams without shear reinforcement}

While the principal tensile stress at any point reaches the tensile strength of concrete, a crack will occur and open normal to the direction of the principal tensile stress or in a parallel direction to the principal compressive stress. Hence, concrete members subjected to shear forces at ultimate load regularly have inclined cracks named diagonal cracks or shear cracks. Inclined cracks can be started in the web of beams where is proved to be the greatest shear stress region and named web shear cracks. Inclined cracks formed from former flexural cracks are called flexureshear cracks as shown in Figure (1). [19] performance of the neural network in predicting the shear strength is much more accurate than those

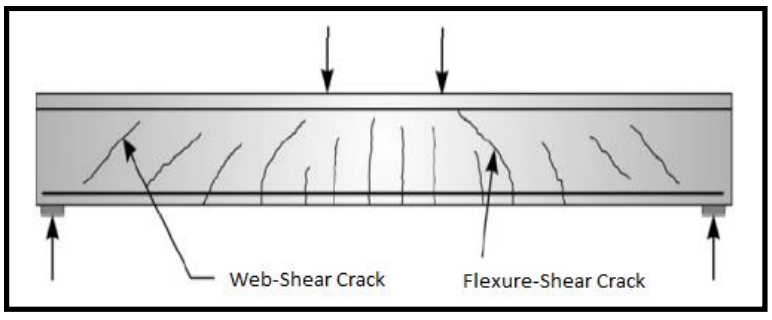

Figure (1) Types of inclined cracks.

The type of failure caused by these cracks, habitually in a very brittle and abrupt way, is termed diagonal failure or shear failure. Usually, there are five different forms of failure caused by diagonal cracks depending on the dimensions, geometries, kind of loading, amount of longitudinal reinforcement and structural characteristics of concrete members as shown in Figure (2), the failure forms are:

1) Diagonal tension failure.

2) Shear compression failure.

3) Shear tension failure.

4) Web crushing failure and.

5) Arch rib failure. [20]

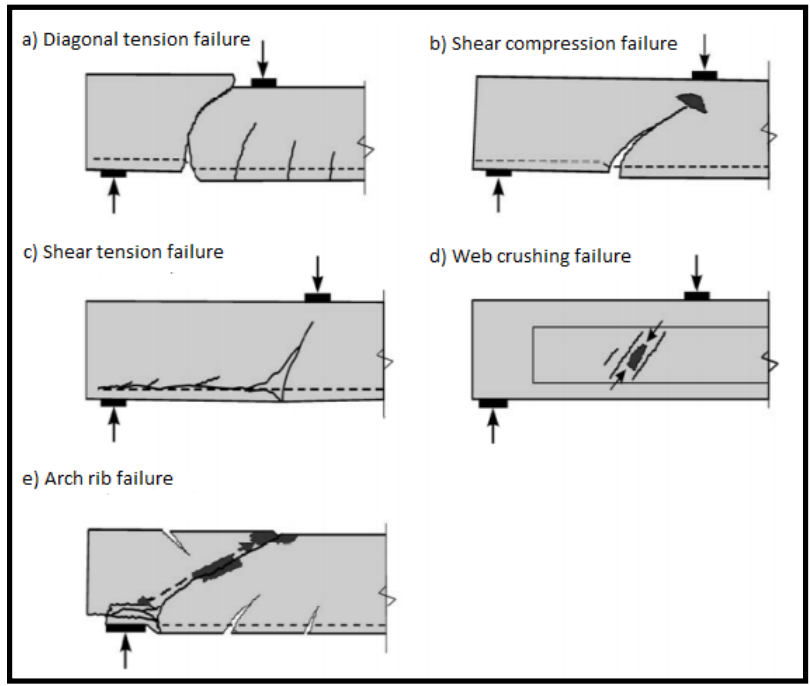

Figure (2) Forms of shear failure of concrete beams.

\subsection{Beams with stirrups}

The crack pattern of slender rectangular beams with stirrups is similar to that of beams without stirrups. In both cases of beams, the critical crack typically includes two branches, which are developed in the 
same region of the beams. It is rational to consider the cause of formation of the second branch of the critical diagonal crack, as well as the corresponding cracking load, are the same in both cases. Up to the formation of the second branch of the critical crack, the effect of stirrups can be negligible. By the increase in the second branch of the critical crack and the strength of the beam, the stirrups are taking action. The continuous opening of the second branch, from the tip of the first branch towards the load point, requires a continuous and gradual increase of the concrete shear force $\mathrm{V}_{\mathrm{ccr}}$ at the beginning of the second branch to balance the grown force $V_{s}$ of stirrups. The concrete shear force at the end of the second branch remains unchanged.

Furthermore, the opening of the second branch of critical crack causes an increase in $\Delta \mathrm{V}_{\mathrm{d}}$ of the shear force of the longitudinal steel bars. Thus, the forces acting at failure on the part of the beam above critical diagonal crack can be regarded to be those shown in Figure (3). Taking into account that the shear force $\mathrm{V}_{\mathrm{cr}}$ at the beginning of cracking of the second branch of the critical crack is equal to the sum $\left(\mathrm{V}_{\mathrm{dcr}}+\mathrm{V}_{\mathrm{ccr}}\right)$, then from the vertical equilibrium of forces acting on the portion of the beam, thus $\mathrm{V}_{\mathrm{u}}$ equal to the sum $\left(\mathrm{V}_{\mathrm{cr}}+\right.$ $\left.\mathrm{V}_{\mathrm{s}}+\Delta \mathrm{V}_{\mathrm{d}}\right)$. [21]

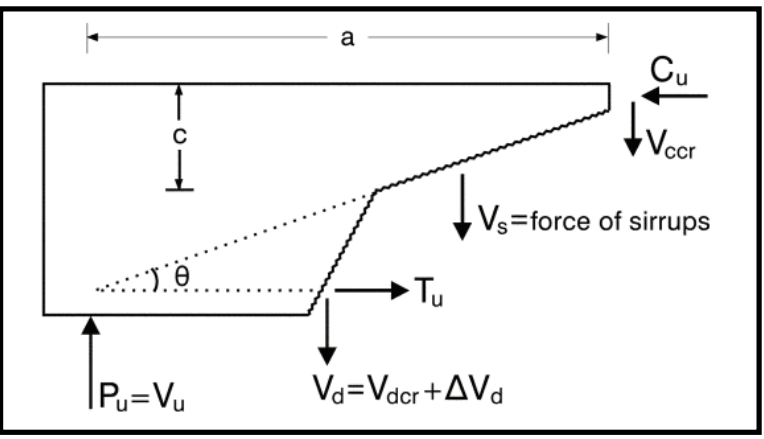

Figure (3) Forces on portion of beam with stirrups above critical diagonal crack at failure.

\section{Prediction of shear strength of concrete 4.1. Empirical codes \\ 4.1.1. American concrete institute (ACI 318-14)[9]}

For reinforced concrete beams with stirrups and with rather large shear span to depth ratio, ACI 31814(2014) simply evaluates shear strength as sum of concrete and stirrup contributions $\left(\mathrm{V}_{\mathrm{c}}\right.$ and $\mathrm{V}_{\mathrm{s}}$, respectively). The predicted shear strength are presented in Table A2. In preparing the values of this table, the expression of the code is used without including in it any safety factor. Thus, for ACI Code predictions (in SI units)

$V_{c}=\left(0.16 * \lambda * \sqrt{f_{c}^{\prime}}+17 * \rho * \frac{V_{u} d}{M_{u}}\right) b_{w} d \leq$

$0.29 * \sqrt{f_{c}^{\prime}} * b_{w} d$

where $\frac{V_{u} d}{M_{u}} \leq 1$

$V_{s}=A_{v} f_{y v} d / s$

$V=V_{c}+V_{s}$

$\rho_{v}=A_{v} / b_{w} S$

$V=b_{w} d\left(0.16 * \lambda * \sqrt{f_{c}^{\prime}}+17 * \rho * \frac{V_{u} d}{M_{u}}+\rho_{v} f_{y v}\right)$

Where $\lambda$ is the factor to account for low-density concrete and equal 1.00 for normal density concrete, $f_{c}^{\prime}$ is the compressive strength of concrete, $V_{u}$ is the factored shear strength at the section, $M_{u}$ is the factored moment at the section, $b_{w}$ is beams web width in $\mathrm{mm}, \mathrm{d}$ effective depth of beams in $\mathrm{mm}, A_{v}$ is the area of vertical stirrups within a distance s, Where $\rho$ is the ratio of main tension reinforcement, $\rho_{v}$ is the ratio of shear reinforcement, $f_{y v}$ is the yield strength of shear reinforcement. As Shown in Figure (4).

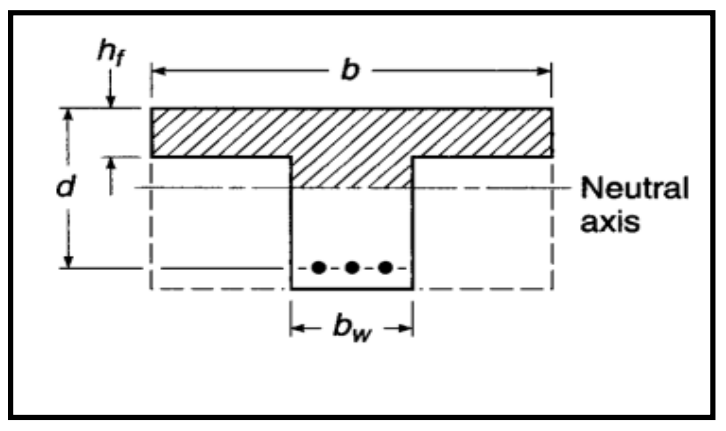

Figure (4) Cross section of T-beam.

\subsubsection{Canadian Standards Association CSA A23.3 (2014)[10]}


CSA A23.3 (2014) is based on the variable truss angle model and the effect of deformation of web due to flexure on evaluating the contribution of concrete and stirrups for shear strength since it was developed through simplifying the Modified Compression Field Theory, which can consider compatibility and equilibrium together.

$V_{c}=\emptyset_{c} \lambda \beta \sqrt{f_{c}^{\prime}} b_{w} d_{v}$

$V_{s}=\emptyset_{s} A_{v} f_{y} d_{v} \cot \theta / s$

The total shear strength $(\mathrm{V})$ is sum of $\mathrm{V}_{\mathrm{c}}$ and $\mathrm{V}_{\mathrm{s}}$, thus

$V=b_{w} d_{v}\left(\emptyset_{c} \lambda \beta * \sqrt{f_{c}^{\prime}}+\emptyset_{s} \rho_{v} f_{y} \cot \theta / s\right)$

Where $\theta$ is the Main diagonal angle which shall be taken as $35^{\circ}$ (for $f_{c}^{\prime}$ does not exceed $60 \mathrm{MPa}$ ), $\beta$ is the factor accounting for shear resistance of cracked concrete, equal $0.18, \emptyset_{c}$ is the resistance factor for concrete, equal $0.65, \emptyset_{s}$ is the resistance factor for nonprestressed reinforcing bars, equal $0.85, \lambda$ is the factor to account for low-density concrete, equal 1.00 for normal density concrete, $d_{v}$ is the effective shear depth.

\subsubsection{Ioannis et al (2006) [22]}

They presented a theory for the shear resistance of reinforced concrete T-beams. The theory was an extension of the theory of slender rectangular beams. It gave an expression showed that the shear strength of slender T-beams is a superposition of the shear strength of T-beams with and without shear reinforcement. An effective width suitable for predicting the shear strength of T-beams is used in this expression. Also, a correction factor to account for the size effect is included in that expression. This expression is a generalized one, valid for T-beams as well as for rectangular beams and it is:

$V=\left[\left(1.2-0.2 \frac{a}{d} d\right) \frac{b_{e f}}{b_{w}} \times \frac{c}{d} f_{c t}+(0.5+\right.$

$\left.\left.2.5 \frac{a}{d}\right) \rho_{v} f_{y v}\right] b_{w} d$

The effective width $b_{e f}$ is given by:

$b_{e f}=b_{w}\left[1+0.5 \times \frac{h_{f}}{d}\left(\frac{b}{b_{w}}-1\right) / \frac{c}{d}\right]$

The depth $\mathrm{c}$ of the compression zone is given by the positive root of the following equation: $\left(\frac{c}{d}\right)^{2}+\left[1.5 \frac{h_{f}}{d}\left(\frac{b}{b_{w}}-1\right)+600 \frac{\rho+\rho^{\prime}}{f_{c}^{\prime}}\right] \times \frac{c}{d}-$

$600 \frac{\rho+\frac{\rho^{\prime} d^{\prime}}{d}}{f_{c}^{\prime}}=0$

The splitting tensile strength of concrete $\left(f_{c t}\right)$ is calculated from

$f_{c t}=0.3 f_{c}^{2 / 3}$

Where, $\rho$ is the ratio of main tension reinforcement, which equals $\mathrm{A}_{\mathrm{s}} / \mathrm{b}_{\mathrm{w}} \mathrm{d}, \rho^{\prime}$ is the ratio of compression reinforcement which equals $A_{s}^{\prime} / b_{w} d, \mathrm{~A}_{s}$ is the area of tension reinforcement, $A_{s}^{\prime}$ is the area of compression reinforcement, $a / d$ is the shear span to depth ratio, $\mathrm{d}$ is the effective depth of beam, $d^{\prime}$ is the effective depth to compression reinforcement and $h_{f}$ is the flange thickness.

\subsection{Artificial Neural Networks Models}

Artificial Neural Networks get their name from nerve cells networks of the brain. They represent a simple version of the human brain. These computational models provide new directions to solve arising problems. In contrast to digital computers, ANNs involve parallel processing which gains computers an additional advantage to simultaneously process of large data. If enough data are available, ANNs are suitable for problems whose solutions require knowledge which is difficult to extract [23]. The neural networks have the ability to learn from experience without needing prior knowledge about the governing relationships and to generalize approximates of any functional relationship with reasonable accuracy. It has been reported that the patterns in a phenomenon can be recognized by the ability of ANN and overcome the difficulties due to the selection of the model form, such as linear, polynomial or power [24].

In many of proposed ANN-approaches, multilayer feed forward-back propagation neural network (MFBPNN) has been applied as shown in figure (5). Typical MFBPNN often has one or more hidden layers with a sigmoid transfer function which followed by an output layer of linear neurons [25]. Multiple layers of neurons with nonlinear activation functions permit the network to learn intricate nonlinear relationships between input and output vectors. Neurons in the hidden layer were connected to previous and next layer by network weights and biases. Application of training function would adjust the network weights 
matrix for each epoch. There are three common backpropagation training algorithms, they are Levenberg Marquardt (trainlm), Bayesian Regularization (trainbr) and scaled conjugate gradient method (trainscg). [26]

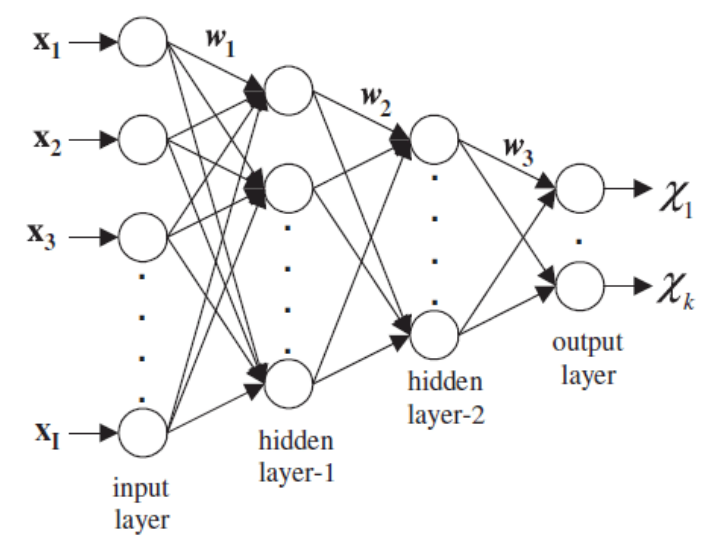

Figure (5) Artificial neural network with two hidden layers.

\section{Methodology}

In this study, an experimental database including 70 concrete T-beams has been investigated [22, 26 and 27]. Parameters of the experimental tests database and its range are presented in Table (1). The entire experimental database could be found in Appendix (A) table (A1).

Table (1). The range of parameters in the database.

\begin{tabular}{|l|c|}
\hline Parameters & Range \\
\hline $\begin{array}{l}\text { Compressive strength of } \\
\text { concrete }\left(f_{c}^{\prime}\right) \mathrm{MPa}\end{array}$ & $12-57$ \\
\hline Beam's web width $\left(\mathrm{b}_{\mathrm{w}}\right) \mathrm{mm}$ & $50-300$ \\
\hline Effective depth of beam $(\mathrm{d}) \mathrm{mm}$ & $240-399$ \\
\hline Beam's flange width $(\mathrm{b}) \mathrm{mm}$ & $200-960$ \\
\hline Flange thickness $\left(\mathrm{h}_{\mathrm{f}}\right) \mathrm{mm}$ & $0-102$ \\
\hline Shear span to depth ratios $(\mathrm{a} / \mathrm{d})$ & $3.33-10.4$ \\
\hline Longitudinal steel ratio $(\rho) \%$ & $0.49-8.34$ \\
\hline $\begin{array}{l}\text { ratio of shear reinforcement } \\
\text { multiplied by the yield strength of } \\
\text { shear reinforcement }\left(\rho_{\mathrm{v}} \mathrm{f}_{\mathrm{yv}}\right) \mathrm{MPa}\end{array}$ & $0-3.46$ \\
\hline Shear strength $\left(\mathrm{V}_{\mathrm{n}}\right) \mathrm{kN}$ & $19-347.5$ \\
\hline
\end{tabular}

An (MFBPNN) model was developed to predict the shear strength of reinforced concrete T-beams and to investigate the interaction effects of the input parameters. The model has eight inputs which are compressive strength of concrete $\left(f_{c}^{\prime}\right)$ in $\mathrm{MPa}$, beams web width $\left(b_{w}\right)$ in $\mathrm{mm}$, effective depth of beams $(d)$ $\mathrm{mm}$, Beams flange width (b) in $\mathrm{mm}$, flange thickness $\left(\mathrm{h}_{\mathrm{f}}\right)$ in $\mathrm{mm}$, shear span to depth ratios $(\mathrm{a} / \mathrm{d})$, longitudinal steel ratio $(\rho)$ as percentage $\%$ and the ratio of shear reinforcement multiplied by the yield strength of shear reinforcement $\left(\rho_{\mathrm{v}} \mathrm{f}_{\mathrm{yv}}\right)$ in $\mathrm{MPa}$. The output of the model was the shear strength in $\mathrm{kN}$.

The network must be trained with an appropriate training function. The main objective of training the neural network is to specify the connection weights by reducing the errors between the predicted and actual target values to an adequate level. Through the minimization of the defined error function, which was Standard Mean Squared Error (Standard MSE), by updating the connection weights. Also, the data was normalization, the number of hidden layers, the number of hidden neurons and the type of transfer functions are chosen to get the best performance of the model. The training function was Bayesian regularization (trainbr) and the model consists of three hidden layers. The first and the third hidden layer with four neurons and the second hidden layer with seven neurons. The activation function of the hidden layers was the Log-sigmoid function (logsig). The model has one output layer with linear transfer function (purelin). The best training performance of the proposed ANN was at Standard MSE equals to $1.73 * 10^{-3}$ as shown in Figure (6). The network performance also has been checked for training, testing data set and for all data, as shown in Figures ( $7 \mathrm{a}, \mathrm{b}$ and $\mathrm{c}$ ). A good agreement has been observed in the predicting values compared with the actual (targets) values.

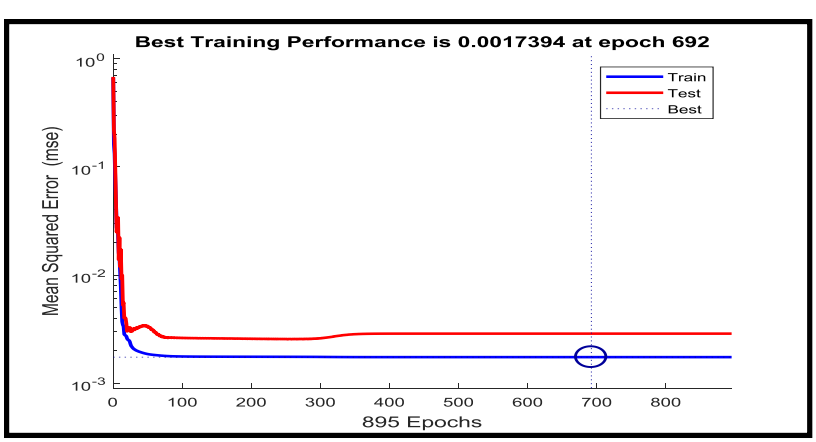

Figure (6) Convergence of the ANN for training and testing sets. 

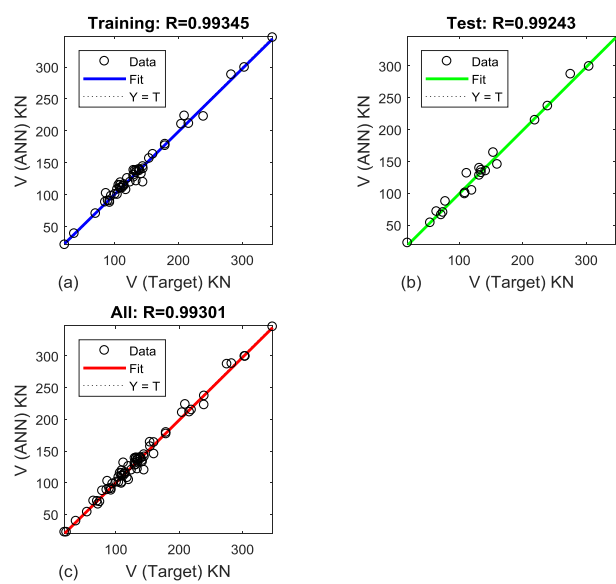

Figure (7) Comparison between ANN results and target results for (a) Training data set sets, (b) Testing data set and (c) All data.

\section{Results and Discussions \\ 6.1. Comparison between experimental and theoretical results}

The experimental database was utilized to evaluate the precision of shear strength of proposed method (ANN) and to compare the ANN prediction with existing equations, the ratio $\left(\mathrm{V}_{\text {th }} / \mathrm{V}_{\text {exp }}\right)$ was used (the whole results could be found in Appendix B). $V_{\text {th }}$ and $\mathrm{V}_{\exp }$ are the shear strength of $\mathrm{T}$-beam based on prediction models and experimental works, respectively. Mean and standard deviation (SD) of the shear strength ratio $\left(\mathrm{V}_{\text {th }} / \mathrm{V}_{\exp }\right)$ are calculated. In addition to that, Correlation coefficients $(\mathrm{R})$ and Mean Absolute Error (MAE) between predicted and experimental shear strength are used as another comparing tool. If the mean value of $\left(\mathrm{V}_{\text {th }} / \mathrm{V}_{\exp }\right)$ and Correlation coefficients $(\mathrm{R})$ are close to one and the standard deviation and Mean Absolute Error (MAE) is small, it will give an indication of what the good ability to generalize the information. The results showed, according to the four indicators, that the best prediction is achieved by the proposed ANN model so it can be used to obtain more accurate results. As shown in Table (2), Figure (8) and appendix (A) Table (A2).
Table (2). Comparison between existing equations and the Proposed ANN.

\begin{tabular}{|c|c|c|c|c|}
\hline The Indicator & $\begin{array}{c}\text { ACI } \\
318-14\end{array}$ & $\begin{array}{c}\text { CSA } \\
\text { A23.3 }\end{array}$ & $\begin{array}{c}\text { Ioannis } \\
\text { et al }\end{array}$ & $\begin{array}{c}\text { Proposed } \\
\text { ANN }\end{array}$ \\
\hline $\begin{array}{c}\text { Mean of } \\
\text { V(th/exp) }\end{array}$ & 0.6409 & 0.6636 & 1.0163 & 1.0023 \\
\hline $\begin{array}{c}\text { Standard } \\
\text { deviation of } \\
\text { V(th/exp) }\end{array}$ & 0.1696 & 0.1680 & 0.0910 & 0.0633 \\
\hline $\begin{array}{c}\text { Correlation } \\
\text { coefficients (R) } \\
\text { with Experimental } \\
\text { V }\end{array}$ & 0.8977 & 0.9445 & 0.9851 & 0.9930 \\
\hline $\begin{array}{c}\text { Mean Absolute } \\
\text { Error (MAE) }\end{array}$ & 51.2617 & 41.4218 & 8.8700 & 5.4862 \\
\hline
\end{tabular}

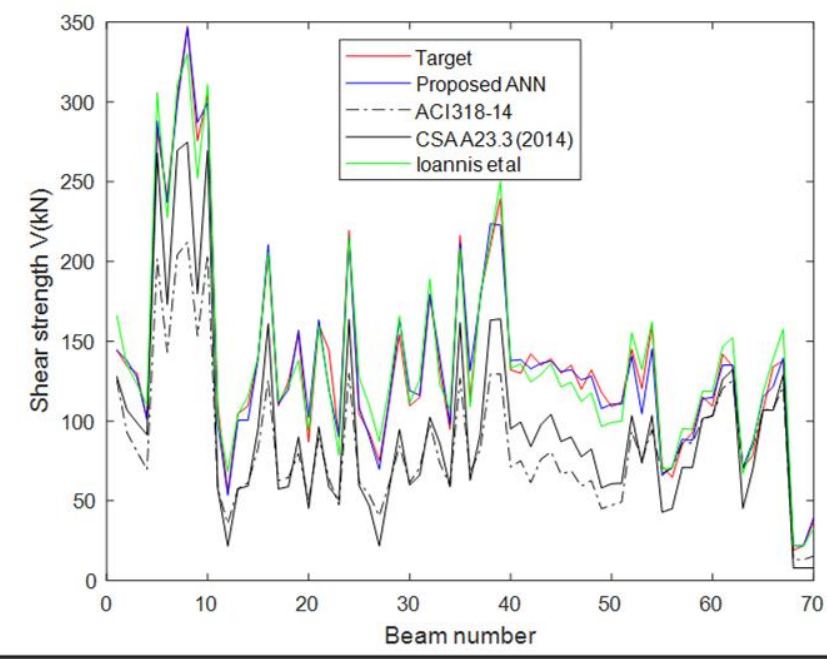

Figure (8) Comparison of experimental and predicted values for Proposed ANN,'ACI 318-14, CSA A23.3 (2014) and Ioannis et al.

\subsection{Parametric analyses based on ANN}

When the artificial neural network has been trained, a parametric analysis is used to study the impact of the multiple parameters on the shear strength of T-beams. The fundamental idea is to predict the effect of a range of values for only one variable while the remaining variables are kept constant and then investigate with a good trained ANN. The maximum and the minimum value of each parameter was summed and divided by two to get the constant value for the seven parameters 
while the eighth one change from minimum to maximum exist values, that is for the input parameters to get its effect on the output parameter which is the shear strength.

In Figure (9) shear strength of concrete of T- beams is plotted versus shear span to depth ratios $(\mathrm{a} / \mathrm{d})$. It can be clearly seen from the figure that the increase in the ratios $(\mathrm{a} / \mathrm{d})$ leads the shear strength to decrease. It can be noticed from the Figure (10) and Figure (11) that the shear strength variation is nonlinear with both the effective depth of the T-beam (d) and ratio of shear reinforcement multiplied by the yield strength of shear reinforcement $\left(\rho_{\mathrm{v}} f_{\mathrm{yv}}\right)$ and as the effects of $(d)$ or $\left(\rho_{\mathrm{v}}\right.$ $f_{y v}$ ) increases, the shear strength increases. It is recognized from the Figure (12) that flange thickness $\left(h_{f}\right)$ has a very clear nonlinear effect on the shear strength of concrete $\mathrm{T}$ - beams. the relationship has a positive pattern with a rather fixed shear effect range of $\left(\mathrm{h}_{\mathrm{f}}\right)$ from (60 to 80$) \mathrm{mm}$. Figures (13) to (16) display a semilinear positive effects between shear strength of concrete T- beams and each of compressive strength of concrete $\left(f_{c}^{\prime}\right)$, Longitudinal steel ratio $(\rho) \%$, Beams flange width (b) and Beams web width $\left(b_{\mathrm{w}}\right)$. Which is in general agreement with the experimental results and $[9,10$ and 22] and that is a good validation check of the ANN in addition to the mentioned statistical results.

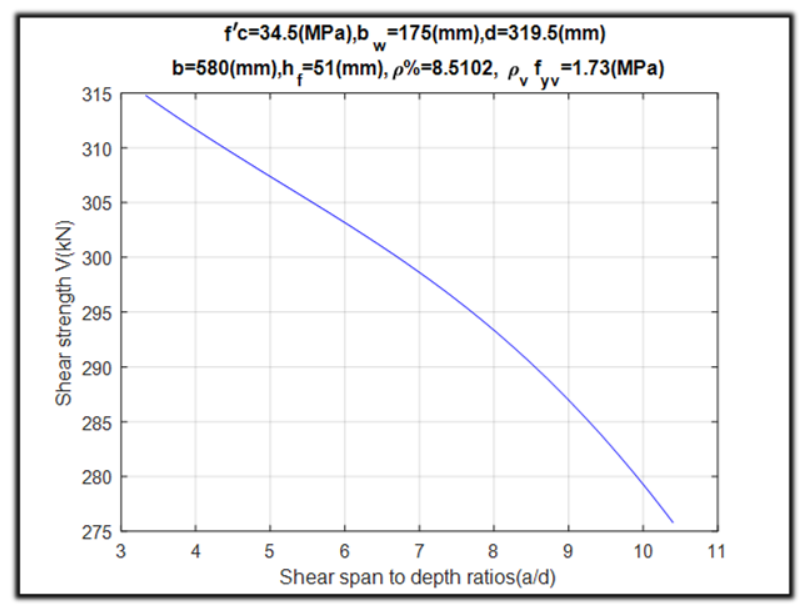

Figure (9) Effect the shear span to depth ratios (a/d) on shear strength of $\mathrm{T}$ beams.

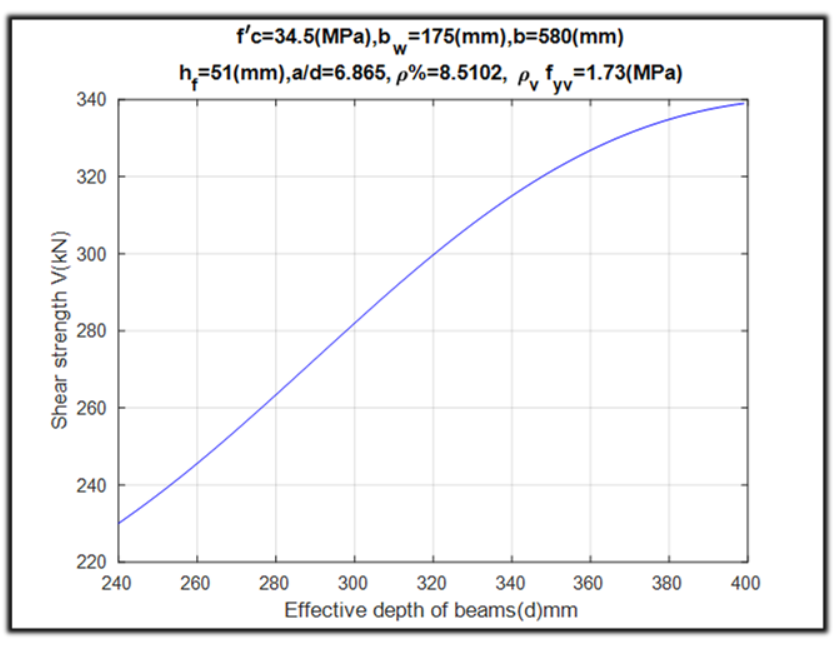

Figure (10) Effect the effective depth (d) on shear strength of $\mathrm{T}$ beams.

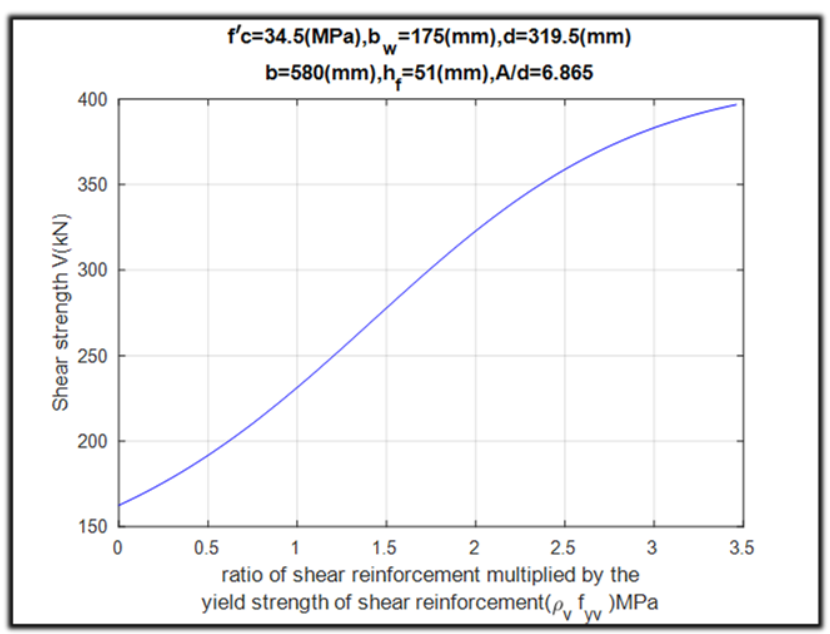

Figure (11) Effect the ratio of shear reinforcement multiplied by the yield strength of shear reinforcement $\left(\rho_{v} f_{y v}\right)$ on shear strength of $T$ beams. 


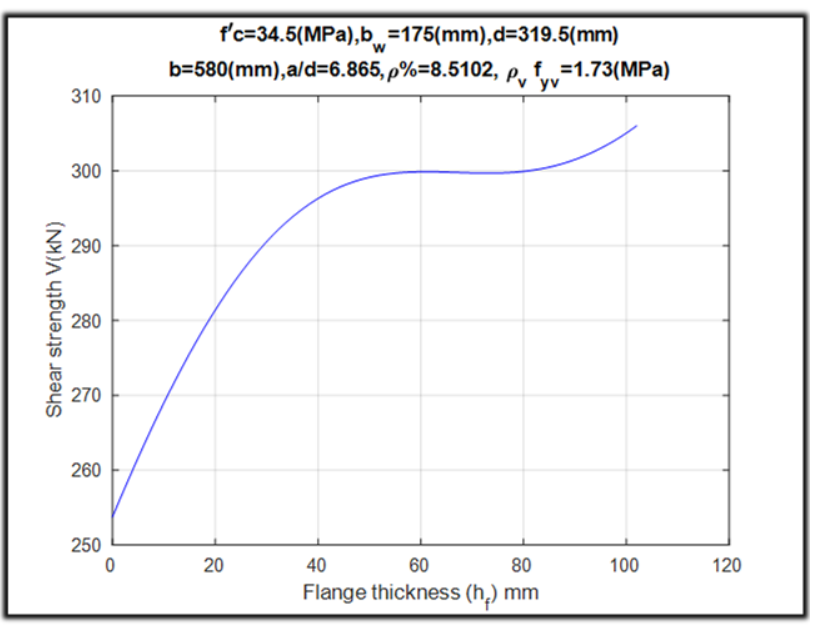

Figure (12) Effect the flange thickness $\left(\mathrm{h}_{\mathrm{f}}\right)$ on shear strength of $\mathrm{T}$ beams.

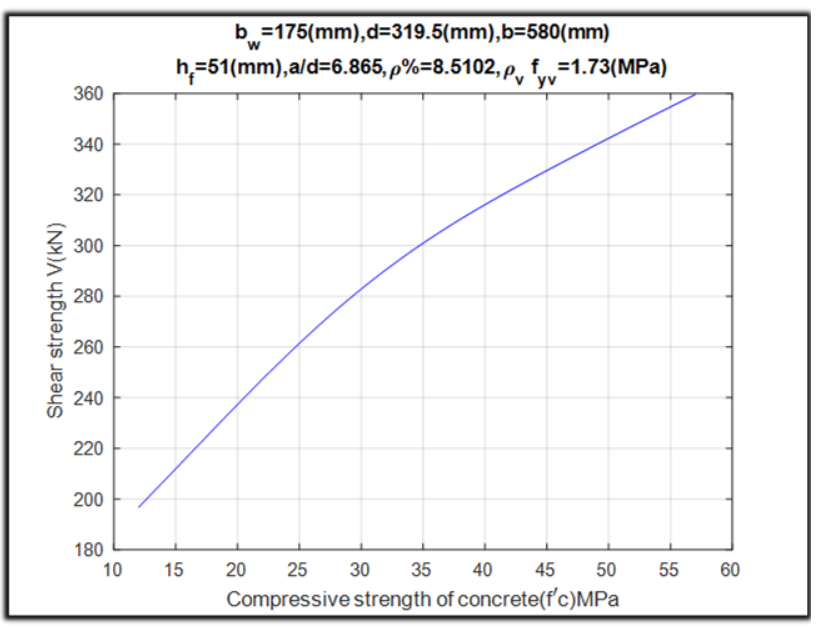

Figure (13) Effect the compressive strength of concrete $\left(f_{c}^{\prime}\right)$ on shear strength of T-beams.

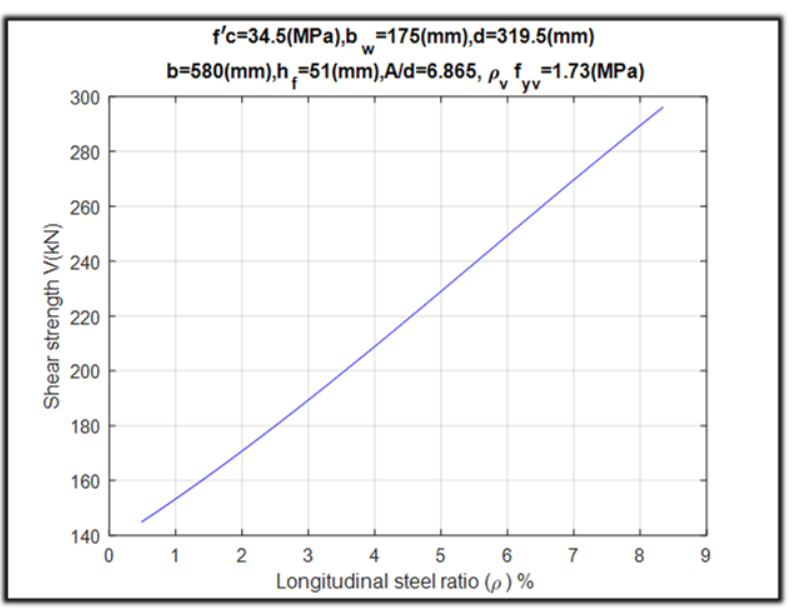

Figure (14) Effect the Longitudinal steel ratio ( $\rho$ ) \% on shear strength of $\mathrm{T}$ beams.

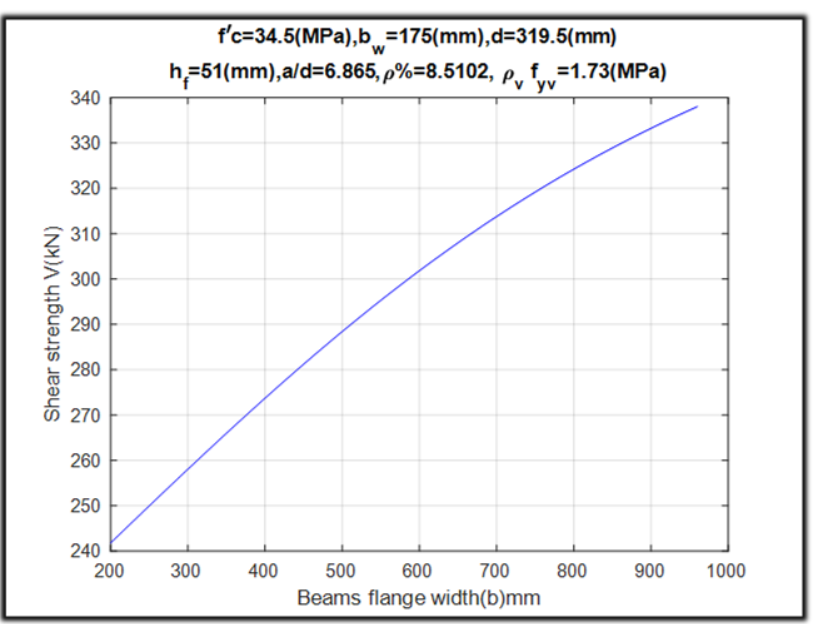

Figure (15) Effect the Beams flange width (b) on shear strength of $\mathrm{T}$ beams

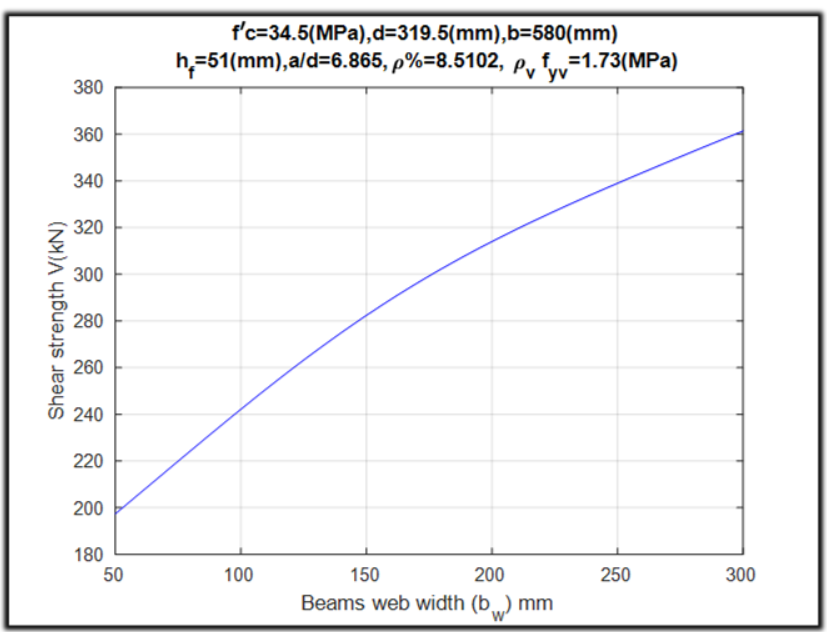

Figure (16) Effect the Beams web width $\left(b_{w}\right)$ on shear strength of $\mathrm{T}$ beams.

\section{Conclusion}

This present study can be regarded as enrichment to a continuous effort to develop artificial neural network system for resolving the civil engineering problems. In this investigation, the model based on an Artificial Neural Network (ANN) is developed to predict the shear strength of T-beams. The database consists of a seventy tests data acquired from the review of the literature. The ANN model has eight inputs variables with one target variable which is the shear strength of concrete T-beams. The comparison between the experimental results and predictions 
showed that the proposed ANN model well predicted the actual shear strength of reinforced concrete $\mathrm{T}$ beams while the shear design provisions such as ACI 318-14 and CSA A23.3 showed notable scatter on the predictions. Also empirical equation for Ioannis et al is more accurate than the two shear design provisions, in the other hand, it less accuracy and more intricacy when compared with ANN model, so we can conclude that the multilayer feed forward back propagation neural network is the most suitable way to predict the shear strength of $\mathrm{T}$-beams than the other three discussed methods.

\section{References}

[1] Kim, K. S. (2004), "Shear behavior of reinforced concrete beams and prestressed concrete beams", Doctorate thesis. Champaign, IL: Civil and Environmental Engineering, University of Illinois at Urbana-Champaign.

[2] Lee, S.C., Cho, J.Y. and Oh, B.H. (2010). "Shear behavior of large-scale post-tensioned girders with small shear span-depth ratio", ACI Structural Journal, 107(2), 137-145.

[3] Labib, E. L., Mo, Y. L., \& Hsu, T. T. C. (2013)," Shear cracking of prestressed girders with high strength concrete", International Journal of Concrete Structures and Materials, 7(1), 71-78.

[4] Russo, G., Mitri, D., \& Pauletta, M. (2013),"'Shear strength design formula for RC beams with stirrups."Engineering Structures, 51, 226-235.

[5] Mofidi, A., \& Chaallal, O. (2014),'Tests and design provisions for reinforced-concrete beams strengthened in shear using FRP sheets and strips", International Journal of Concrete Structures and Materials, 8(1), 117-128.

[6] Jeong, J.P. and Kim, W. (2014),"'Shear resistance mechanism into base components: beam action and arch action in shear-critical RC members", International Journal of Concrete Structures and Materials, 8(1), 1-14.

[7] Chiu, C.K., Ueda, T., Chi, K.N., and Chen, S.Q. (2016),"Shear crack control for high strength reinforced concrete beams considering the effect of shear-span to depth ratio", International Journal of Concrete Structures and Materials, 10(4), 407-424.

[8] El-Sayed, A. K., and Shuraim, A. B. (2016),"Experimental verification of resistancedemand approach for shear of HSC beams,"International Journal of Concrete Structures and Materials, 10(4), 513-525.

[9] ACI Committee 318. (2014),"Building code requirements for structural concrete and commentary," ACI 318-14/ACIR-14. Farmington Hills, MI: American Concrete Institute.

[10] CSA A23.3-14. (2014), "Design of Concrete Structures, Canadian Standards Association", 5060 Spectrum Way, Suite 100, Mississauga, Ontario, Canada, L4W 5NG.

[11] Naderpour, H., Kheyroddin, A. and Amiri, G.G. (2010), "Prediction of FRP-confined compressive strength of concrete using artificial neural networks", Compos. Struct. 92, 2817-2829, http://dx.doi.org/10.1016/j.compstruct.2010.04.008.

[12] Khademi, F., Jamal, S.M., Deshpande, N. and Londhe, S. (2016), "Predicting strength of recycled aggregate concrete using artificial neural network, adaptive neuro-fuzzy inference system and multiple linear regression", Built Environ. 5 (2), 355-369.

[13] Ahmadi, M., Naderpour, H. and Kheyroddin, A. (2014), "Utilization of artificial neural networks to prediction of the capacity of CCFT short columns subject to short term axial load", Arch. Civ. Mech. Eng. $14, \quad 510-517$, http://dx.doi.org/10.1016/j.acme.2014.

[14] Sanad, A. and Saka, M.P. (2001) Prediction of ultimate shear strength of reinforced concrete deep beams using neural networks. J. Structural Eng., $127,818-828$.

[15] Ashour, A.F., Alvarez, L.F. and Toropov, V.V. (2003) "Empirical modeling of shear strength of RC deep beams by genetic programming". Compute Structures, 81, 331-338.

[16] Arafa, M., Alqedra, M. and An-Najjar, H. (2011), "Neural Network Models for Predicting Shear Strength of Reinforced Normal and High-strength Concrete Deep Beams"Journal of applied Sciences, 11(2), 266-274. 


\section{Prediction of the Shear Strength of Concrete T-Beams using Artificial Neural Networks Model}

[17] Amani, J. and Moeini, R. (2012), "Prediction of shear strength of reinforced concrete beams using adaptive neuro-fuzzy inference system and artificial neural network", Scientia Iranica, 19 (2), 242-248.

[18] Vahidi, E. K. and Rahimi, F. (2016), "Investigation of Ultimate Shear Capacity of RC Deep Beams with Opening using Artificial Neural Networks", Advances in Computer Science, 5 (4), No.22.

[19] NCHRP Report 549 (2005), "Simplified Shear Design of Structural Concrete Members"

[20] Raju, I. (2014), "Review on Shear Behavior of Reinforced Concrete Beam without Transverse Reinforcement" Journal of Engineering Research and Applications, 4 (4), 116-121.

[21] Zararis, P. D. (2003), "Shear Strength and Minimum Shear Reinforcement of Reinforced Concrete Slender Beams," ACI Structural Journal, 100, (2), 203-214.
[22] Ioannis, P. Z., Maria, K. K. and Prodromos, D. Z. (2006),"Shear Strength of Reinforced Concrete TBeams", ACI Structural Journal, pp. 693-700.

[23] Zhang, B.E. Patuwo and M.Y. Hu (1998), "Forecasting with Artificial

Neural Networks", the State of the Art, International Journal of Forecasting , 14, 35-62.

[24] Tokar, A.S. and Johnson, P.A. (1999), "RainfallRunoff Modeling using Artificial Neural Networks", Journal of Hydrologic Engineering, 4(3), 232-239 [25] Beale, M.H., Hagan, M.T. and Demuth, H.B. (2017), "Neural Network Toolbox: User's Guide", MathWorks, Inc.

[26] Palaskas, M. N., Attiogbe, E. K. and Darwin, D. (1981), "Shear Strength of Lightly Reinforced TBeams", ACI journal, Proceedings V. 78, No. 6, Nov.Dec., 447-455.

[27] Kotsovos, M. D., Bobrowski, J. and Eibl, J. (1987), "Behaviour of Reinforced Concrete T-Beams in Shear", the Instruction of Structural Engineers, 65B, $1-10$. 
Appendix A

Table A1: experimental database including 70 concrete T-beams:

\begin{tabular}{|c|c|c|c|c|c|c|c|c|c|}
\hline $\begin{array}{c}\text { Beam } \\
\text { NO }\end{array}$ & $\begin{array}{c}f_{c}^{\prime} \\
(\mathrm{Mpa})\end{array}$ & $\begin{array}{c}\mathrm{b}_{\mathrm{w}} \\
(\mathrm{mm})\end{array}$ & $\underset{(\mathrm{mm})}{\mathrm{d}}$ & $\begin{array}{c}\mathrm{b} \\
(\mathrm{mm})\end{array}$ & $\begin{array}{c}\mathrm{h}_{\mathrm{f}} \\
(\mathrm{mm})\end{array}$ & $\mathrm{a} / \mathrm{d}$ & $\rho \%$ & $\begin{array}{l}\rho_{\mathrm{v}} \mathrm{f}_{\mathrm{yv}} \\
(\mathrm{Mpa})\end{array}$ & $\begin{array}{l}\mathrm{V} \mathrm{kN} \\
(\exp )\end{array}$ \\
\hline 1 & 22.6 & 300 & 300 & 300 & 0 & 3.5 & 1.39 & 0.57 & 144.5 \\
\hline 2 & 23 & 150 & 300 & 300 & 75 & 3.5 & 2.78 & 1.16 & 134.5 \\
\hline 3 & 23 & 100 & 300 & 300 & 75 & 3.5 & 4.17 & 1.73 & 130 \\
\hline 4 & 23 & 50 & 300 & 300 & 75 & 3.5 & 8.34 & 3.46 & 101 \\
\hline 5 & 15.4 & 160 & 375 & 960 & 80 & 3.33 & 4.4 & 2.51 & 283 \\
\hline 6 & 15.4 & 160 & 375 & 960 & 80 & 3.33 & 4.4 & 1.53 & 239.5 \\
\hline 7 & 17.4 & 160 & 375 & 960 & 80 & 3.33 & 4.4 & 2.51 & 303.5 \\
\hline 8 & 24.9 & 160 & 375 & 960 & 80 & 3.33 & 4.4 & 2.51 & 347.5 \\
\hline 9 & 24.9 & 160 & 375 & 960 & 80 & 3.33 & 4.4 & 1.53 & 275.5 \\
\hline 10 & 17.4 & 160 & 375 & 960 & 80 & 3.33 & 4.4 & 2.51 & 304.5 \\
\hline 11 & 27.9 & 152 & 254 & 610 & 76 & 3.36 & 1.25 & 0.58 & 109 \\
\hline 12 & 28.1 & 152 & 254 & 610 & 76 & 3.36 & 1.46 & 0 & 54.7 \\
\hline 13 & 27.5 & 152 & 254 & 610 & 76 & 3.36 & 1.46 & 0.58 & 104.6 \\
\hline 14 & 32.5 & 152 & 254 & 610 & 76 & 3.36 & 1.95 & 0.58 & 109.5 \\
\hline 15 & 33.7 & 152 & 254 & 610 & 76 & 3.36 & 1.46 & 1.15 & 139.7 \\
\hline 16 & 25.8 & 152 & 254 & 610 & 76 & 3.6 & 4.16 & 2.25 & 204.7 \\
\hline 17 & 27.4 & 152 & 254 & 610 & 76 & 3.46 & 3 & 0.58 & 109.5 \\
\hline 18 & 31.3 & 152 & 254 & 610 & 76 & 3.6 & 4.16 & 0.58 & 124.6 \\
\hline 19 & 20.2 & 152 & 254 & 610 & 76 & 3.6 & 4.16 & 1.15 & 154.4 \\
\hline 20 & 28.2 & 152 & 254 & 610 & 76 & 3.36 & 4.16 & 0.38 & 86.8 \\
\hline 21 & 37 & 152 & 254 & 610 & 76 & 3.6 & 4.16 & 1.15 & 160.2 \\
\hline 22 & 30.7 & 152 & 254 & 610 & 76 & 3.6 & 4.16 & 0.58 & 144.6 \\
\hline 23 & 12.8 & 152 & 254 & 610 & 76 & 3.36 & 4.16 & 0.58 & 89.9 \\
\hline 24 & 33.4 & 152 & 254 & 610 & 76 & 3.6 & 4.16 & 2.25 & 219.4 \\
\hline 25 & 33.2 & 152 & 254 & 610 & 76 & 7.2 & 4.16 & 0.58 & 104.5 \\
\hline 26 & 32.7 & 152 & 254 & 610 & 76 & 7.2 & 4.16 & 0.38 & 92.6 \\
\hline 27 & 28.4 & 152 & 254 & 610 & 76 & 3.6 & 4.16 & 0 & 74.8 \\
\hline 28 & 30 & 152 & 254 & 610 & 76 & 5.4 & 4.16 & 0.58 & 113.5 \\
\hline 29 & 32.1 & 152 & 254 & 610 & 76 & 5.4 & 4.16 & 1.15 & 154 \\
\hline 30 & 34.4 & 152 & 254 & 610 & 76 & 3.36 & 4.16 & 0.58 & 109.5 \\
\hline 31 & 54.1 & 152 & 254 & 610 & 76 & 3.36 & 4.16 & 0.58 & 114.8 \\
\hline 32 & 57 & 152 & 254 & 610 & 76 & 3.6 & 4.16 & 1.15 & 179.3 \\
\hline 33 & 12 & 152 & 254 & 610 & 76 & 3.6 & 4.16 & 1.15 & 132.1 \\
\hline 34 & 31 & 152 & 254 & 610 & 76 & 3.36 & 1.46 & 0.58 & 94.8 \\
\hline 35 & 27.6 & 152 & 254 & 610 & 76 & 3.6 & 4.16 & 2.25 & 216.3 \\
\hline 36 & 43 & 152 & 254 & 400 & 80 & 5.4 & 4.16 & 0.58 & 112.1 \\
\hline 37 & 24.2 & 152 & 254 & 400 & 80 & 3.6 & 4.16 & 1.15 & 179.3 \\
\hline 38 & 31.8 & 152 & 254 & 400 & 80 & 3.6 & 4.16 & 2.25 & 209.6 \\
\hline 39 & 30.2 & 152 & 256 & 400 & 80 & 3.6 & 4.16 & 2.25 & 239.4 \\
\hline 40 & 33.1 & 110 & 298 & 400 & 80 & 3.5 & 3.84 & 1.42 & 132 \\
\hline 41 & 31.7 & 110 & 298 & 400 & 80 & 3.5 & 3.84 & 1.51 & 130 \\
\hline 42 & 34.9 & 110 & 298 & 400 & 80 & 3.5 & 3.84 & 1.2 & 142 \\
\hline 43 & 23.4 & 110 & 298 & 400 & 80 & 3.5 & 3.84 & 1.53 & 135 \\
\hline 44 & 25.1 & 110 & 298 & 400 & 80 & 3.5 & 3.84 & 1.64 & 139 \\
\hline 45 & 25.1 & 110 & 298 & 400 & 80 & 3.5 & 3.84 & 1.32 & 130 \\
\hline 46 & 25.7 & 110 & 298 & 400 & 80 & 3.5 & 3.84 & 1.37 & 135 \\
\hline 47 & 23.6 & 110 & 298 & 400 & 80 & 3.5 & 3.84 & 1.15 & 120 \\
\hline
\end{tabular}




\begin{tabular}{|c|c|c|c|c|c|c|c|c|c|}
\hline 48 & 25.4 & 110 & 298 & 400 & 80 & 3.5 & 3.84 & 1.23 & 132 \\
\hline 49 & 25.1 & 110 & 298 & 400 & 80 & 3.5 & 3.84 & 0.77 & 118 \\
\hline 50 & 25.2 & 110 & 298 & 400 & 80 & 3.5 & 3.84 & 0.82 & 109 \\
\hline 51 & 26 & 110 & 298 & 400 & 80 & 3.5 & 3.84 & 0.82 & 112 \\
\hline 52 & 43 & 150 & 285 & 600 & 80 & 3.5 & 1.45 & 1.07 & 145 \\
\hline 53 & 40.7 & 150 & 285 & 600 & 80 & 3.5 & 1.94 & 0.65 & 120.2 \\
\hline 54 & 43.1 & 150 & 285 & 600 & 80 & 3.5 & 1.94 & 1.07 & 160.2 \\
\hline 55 & 32.8 & 190 & 374 & 610 & 102 & 4.14 & 0.69 & 0 & 72 \\
\hline 56 & 32.7 & 190 & 394 & 610 & 102 & 3.92 & 0.66 & 0 & 64.7 \\
\hline 57 & 32.6 & 190 & 390 & 610 & 102 & 3.97 & 0.66 & 0.22 & 85.5 \\
\hline 58 & 33.1 & 190 & 388 & 610 & 102 & 4 & 0.67 & 0.22 & 92.6 \\
\hline 59 & 26.3 & 190 & 392 & 610 & 102 & 3.96 & 0.66 & 0.51 & 115.1 \\
\hline 60 & 28 & 190 & 393 & 610 & 102 & 3.94 & 0.66 & 0.51 & 109.2 \\
\hline 61 & 32.2 & 190 & 395 & 610 & 102 & 3.92 & 0.66 & 0.67 & 141.8 \\
\hline 62 & 38.1 & 190 & 371 & 610 & 102 & 4.18 & 0.7 & 0.76 & 134 \\
\hline 63 & 32 & 190 & 399 & 610 & 102 & 3.88 & 0.49 & 0 & 70.5 \\
\hline 64 & 30.8 & 190 & 394 & 610 & 102 & 3.92 & 0.49 & 0.22 & 78.6 \\
\hline 65 & 30.6 & 190 & 391 & 610 & 102 & 3.96 & 0.5 & 0.53 & 106.6 \\
\hline 66 & 29.7 & 190 & 393 & 610 & 102 & 3.94 & 0.94 & 0.53 & 134 \\
\hline 67 & 29.4 & 190 & 395 & 610 & 102 & 3.92 & 0.93 & 0.71 & 137.7 \\
\hline 68 & 40 & 50 & 240 & 200 & 65 & 10.4 & 5.23 & 0 & 19 \\
\hline 69 & 40 & 50 & 240 & 200 & 65 & 10.4 & 5.23 & 0 & 22 \\
\hline 70 & 40 & 50 & 240 & 200 & 65 & 3.33 & 5.23 & 0 & 37 \\
\hline
\end{tabular}


Table A2: Comparisons of experimental and theoretical results:

\begin{tabular}{|c|c|c|c|c|c|c|c|c|c|}
\hline \multirow{2}{*}{$\begin{array}{l}\text { Beam } \\
\text { NO }\end{array}$} & \multirow{2}{*}{$\begin{array}{c}\text { Experimental } \\
\mathrm{V}(\mathrm{kN})\end{array}$} & \multicolumn{2}{|c|}{ ACI 318-14 } & \multicolumn{2}{|c|}{ CSA } & \multicolumn{2}{|c|}{ Ioannis et al } & \multicolumn{2}{|c|}{ Proposed ANN } \\
\hline & & $\mathrm{V}(\mathrm{kN})$ & $\mathrm{V}(\mathrm{th} / \exp )$ & $\mathrm{V}(\mathrm{kN})$ & $\mathrm{V}(\mathrm{th} / \exp )$ & $\mathrm{V}(\mathrm{kN})$ & $\mathrm{V}(\mathrm{th} / \exp )$ & $\mathrm{V}(\mathrm{kN})$ & $\mathrm{V}(\mathrm{th} / \exp )$ \\
\hline 1 & 144.5 & 125.83 & 0.871 & 127.880 & 0.885 & 166 & 1.149 & 144.280 & 0.998 \\
\hline 2 & 134.5 & 92.81 & 0.690 & 107.005 & 0.796 & 134.9 & 1.003 & 137.935 & 1.026 \\
\hline 3 & 130 & 81.00 & 0.623 & 98.945 & 0.761 & 123.1 & 0.947 & 127.404 & 0.980 \\
\hline 4 & 101 & 69.49 & 0.688 & 91.370 & 0.905 & 110 & 1.089 & 100.945 & 0.999 \\
\hline 5 & 283 & 201.75 & 0.713 & 267.946 & 0.947 & 305.6 & 1.080 & 287.983 & 1.018 \\
\hline 6 & 239.5 & 142.95 & 0.597 & 173.010 & 0.722 & 227.3 & 0.949 & 236.965 & 0.989 \\
\hline 7 & 303.5 & 204.12 & 0.673 & 269.506 & 0.888 & 310.9 & 1.024 & 299.312 & 0.986 \\
\hline 8 & 347.5 & 211.98 & 0.610 & 274.679 & 0.790 & 330.0 & 0.950 & 346.050 & 0.996 \\
\hline 9 & 275.5 & 153.18 & 0.556 & 179.743 & 0.652 & 252.0 & 0.915 & 287.067 & 1.042 \\
\hline 10 & 304.5 & 204.12 & 0.670 & 269.506 & 0.885 & 310.9 & 1.021 & 299.312 & 0.983 \\
\hline 11 & 109 & 57.46 & 0.527 & 57.628 & 0.529 & 101.5 & 0.931 & 98.787 & 0.906 \\
\hline 12 & 54.7 & 35.60 & 0.651 & 21.551 & 0.394 & 68.3 & 1.249 & 53.513 & 0.978 \\
\hline 13 & 104.6 & 57.64 & 0.551 & 57.473 & 0.549 & 104.0 & 0.994 & 100.430 & 0.960 \\
\hline 14 & 109.5 & 61.42 & 0.561 & 59.331 & 0.542 & 115.6 & 1.056 & 100.524 & 0.918 \\
\hline 15 & 139.7 & 83.11 & 0.595 & 95.285 & 0.682 & 140.2 & 1.004 & 139.404 & 0.998 \\
\hline 16 & 204.7 & 125.83 & 0.615 & 160.903 & 0.786 & 205.6 & 1.004 & 210.537 & 1.029 \\
\hline 17 & 109.5 & 62.80 & 0.574 & 57.435 & 0.525 & 112.4 & 1.026 & 110.833 & 1.012 \\
\hline 18 & 124.6 & 64.54 & 0.518 & 58.899 & 0.473 & 121.9 & 0.978 & 119.756 & 0.961 \\
\hline 19 & 154.4 & 79.75 & 0.517 & 89.957 & 0.583 & 138.1 & 0.894 & 156.860 & 1.016 \\
\hline 20 & 86.8 & 50.33 & 0.580 & 45.276 & 0.522 & 94.0 & 1.083 & 102.349 & 1.179 \\
\hline 21 & 160.2 & 89.56 & 0.559 & 96.414 & 0.602 & 159.6 & 0.996 & 163.438 & 1.020 \\
\hline 22 & 144.6 & 64.20 & 0.444 & 58.680 & 0.406 & 121.3 & 0.839 & 119.751 & 0.828 \\
\hline 23 & 89.9 & 47.35 & 0.527 & 50.699 & 0.564 & 78.5 & 0.873 & 90.682 & 1.009 \\
\hline 24 & 219.4 & 130.15 & 0.593 & 163.748 & 0.746 & 215.0 & 0.980 & 214.733 & 0.979 \\
\hline 25 & 104.5 & 61.78 & 0.591 & 59.579 & 0.570 & 127.4 & 1.219 & 108.571 & 1.039 \\
\hline 26 & 92.6 & 53.79 & 0.581 & 46.935 & 0.507 & 109.8 & 1.186 & 90.385 & 0.976 \\
\hline 27 & 74.8 & 40.50 & 0.541 & 21.665 & 0.290 & 87.0 & 1.163 & 69.737 & 0.932 \\
\hline 28 & 113.5 & 61.28 & 0.540 & 58.421 & 0.515 & 121.8 & 1.073 & 113.397 & 0.999 \\
\hline 29 & 154 & 84.45 & 0.548 & 94.718 & 0.615 & 165.8 & 1.077 & 163.863 & 1.064 \\
\hline 30 & 109.5 & 61.48 & 0.561 & 59.998 & 0.548 & 111.2 & 1.016 & 119.072 & 1.087 \\
\hline 31 & 114.8 & 70.68 & 0.616 & 66.056 & 0.575 & 126.0 & 1.098 & 116.138 & 1.012 \\
\hline 32 & 179.3 & 98.62 & 0.550 & 102.378 & 0.571 & 189.0 & 1.054 & 179.284 & 1.000 \\
\hline 33 & 132.1 & 73.38 & 0.555 & 85.768 & 0.649 & 122.7 & 0.929 & 139.351 & 1.055 \\
\hline 34 & 94.8 & 59.64 & 0.629 & 58.789 & 0.620 & 107.0 & 1.129 & 97.994 & 1.034 \\
\hline 35 & 216.3 & 126.91 & 0.587 & 161.611 & 0.747 & 208.0 & 0.962 & 211.400 & 0.977 \\
\hline 36 & 112.1 & 67.96 & 0.606 & 62.813 & 0.560 & 108.7 & 0.970 & 131.351 & 1.172 \\
\hline 37 & 179.3 & 82.37 & 0.459 & 91.684 & 0.511 & 179.4 & 1.001 & 176.824 & 0.986 \\
\hline 38 & 209.6 & 129.29 & 0.617 & 163.179 & 0.779 & 213.0 & 1.016 & 223.539 & 1.067 \\
\hline 39 & 239.4 & 129.41 & 0.541 & 163.875 & 0.685 & 250.0 & 1.044 & 222.681 & 0.930 \\
\hline 40 & 132 & 71.09 & 0.539 & 95.012 & 0.720 & 133.1 & 1.008 & 137.792 & 1.044 \\
\hline 41 & 130 & 75.07 & 0.577 & 99.351 & 0.764 & 135.8 & 1.045 & 138.426 & 1.065 \\
\hline 42 & 142 & 61.36 & 0.432 & 83.902 & 0.591 & 124.4 & 0.876 & 132.674 & 0.934 \\
\hline 43 & 135 & 75.96 & 0.563 & 97.673 & 0.724 & 129.1 & 0.956 & 136.158 & 1.009 \\
\hline 44 & 139 & 80.82 & 0.581 & 104.090 & 0.749 & 135.8 & 0.977 & 137.550 & 0.990 \\
\hline 45 & 130 & 66.66 & 0.513 & 87.154 & 0.670 & 121.4 & 0.934 & 130.829 & 1.006 \\
\hline
\end{tabular}


Prediction of the Shear Strength of Concrete T-Beams using Artificial Neural Networks Model

\begin{tabular}{|l|l|l|l|l|l|l|l|l|l|}
\hline 46 & 135 & 68.88 & 0.510 & 90.006 & 0.667 & 124.2 & 0.920 & 132.100 & 0.979 \\
\hline 47 & 120 & 59.14 & 0.493 & 77.632 & 0.647 & 112.3 & 0.936 & 125.711 & 1.048 \\
\hline 48 & 132 & 62.68 & 0.475 & 82.494 & 0.625 & 117.6 & 0.891 & 128.060 & 0.970 \\
\hline 49 & 118 & 45.02 & 0.382 & 58.045 & 0.492 & 96.5 & 0.818 & 107.793 & 0.913 \\
\hline 50 & 109 & 47.24 & 0.433 & 60.726 & 0.557 & 99.1 & 0.909 & 110.522 & 1.014 \\
\hline 51 & 112 & 49.30 & 0.440 & 60.999 & 0.545 & 99.8 & 0.891 & 110.446 & 0.986 \\
\hline 52 & 145 & 93.61 & 0.646 & 103.373 & 0.713 & 155.3 & 1.071 & 140.771 & 0.971 \\
\hline 53 & 120.2 & 75.45 & 0.628 & 73.583 & 0.612 & 132.2 & 1.100 & 104.453 & 0.869 \\
\hline 54 & 160.2 & 94.68 & 0.591 & 103.407 & 0.645 & 162.2 & 1.012 & 145.233 & 0.907 \\
\hline 55 & 72 & 67.13 & 0.932 & 42.854 & 0.595 & 69.7 & 0.968 & 65.879 & 0.915 \\
\hline 56 & 64.7 & 70.64 & 1.092 & 45.077 & 0.697 & 70.8 & 1.094 & 71.160 & 1.100 \\
\hline 57 & 85.5 & 86.09 & 1.007 & 70.871 & 0.829 & 95.1 & 1.112 & 88.529 & 1.035 \\
\hline 58 & 92.6 & 86.18 & 0.931 & 70.846 & 0.765 & 94.8 & 1.024 & 87.931 & 0.950 \\
\hline 59 & 115.1 & 101.21 & 0.879 & 101.549 & 0.882 & 118.6 & 1.030 & 113.858 & 0.989 \\
\hline 60 & 109.2 & 103.43 & 0.947 & 103.091 & 0.944 & 118.5 & 1.085 & 114.740 & 1.051 \\
\hline 61 & 141.8 & 120.57 & 0.850 & 126.030 & 0.889 & 146.6 & 1.034 & 134.942 & 0.952 \\
\hline 62 & 134 & 125.20 & 0.934 & 132.312 & 0.987 & 152.2 & 1.136 & 135.039 & 1.008 \\
\hline 63 & 70.5 & 70.24 & 0.996 & 45.157 & 0.641 & 67.1 & 0.952 & 70.636 & 1.002 \\
\hline 64 & 78.6 & 84.53 & 1.075 & 70.338 & 0.895 & 85.5 & 1.088 & 87.115 & 1.108 \\
\hline 65 & 106.6 & 106.72 & 1.001 & 106.844 & 1.002 & 118.0 & 1.107 & 115.098 & 1.080 \\
\hline 66 & 134 & 107.71 & 0.804 & 106.746 & 0.797 & 138.9 & 1.037 & 121.544 & 0.907 \\
\hline 67 & 137.7 & 121.42 & 0.882 & 128.883 & 0.936 & 157.6 & 1.145 & 139.539 & 1.013 \\
\hline 68 & 19 & 13.17 & 0.693 & 7.992 & 0.421 & 21.8 & 1.147 & 21.855 & 1.150 \\
\hline 69 & 22 & 13.17 & 0.599 & 7.992 & 0.363 & 21.8 & 0.991 & 21.855 & 0.993 \\
\hline 70 & 37 & 15.35 & 0.415 & 7.992 & 0.216 & 32.4 & 0.876 & 39.286 & 1.062 \\
\hline
\end{tabular}

